\title{
Boundary point algorithms for minimum norm fixed points of nonexpansive mappings
}

\author{
Songnian $\mathrm{He}^{1,2^{*}}$ and Caiping Yang ${ }^{1}$
}

${ }^{*}$ Correspondence:

songnianhe@163.com

${ }^{1}$ College of Science, Civil Aviation

University of China, Tianjin, 300300,

China

${ }^{2}$ Tianjin Key Laboratory for

Advanced Signal Processing, Civil

Aviation University of China, Tianjin,

300300, China

\begin{abstract}
Let $H$ be a real Hilbert space and $C$ be a closed convex subset of $H$. Let $T: C \rightarrow C$ be a nonexpansive mapping with a nonempty set of fixed points Fix ( $T$ ). If $0 \notin C$, then Halpern's iteration process $x_{n+1}=\left(1-t_{n}\right) T x_{n}$ cannot be used for finding a minimum norm fixed point of $T$ since $x_{n}$ may not belong to $C$. To overcome this weakness, Wang and $X u$ introduced the iteration process $x_{n+1}=P_{C}\left(1-t_{n}\right) T x_{n}$ for finding the minimum norm fixed point of $T$, where the sequence $\left\{t_{n}\right\} \subset(0,1), x_{0} \in C$ arbitrarily and $P_{C}$ is the metric projection from $\mathrm{H}$ onto $\mathrm{C}$. However, it is difficult to implement this iteration process in actual computing programs because the specific expression of $P_{C}$ cannot be obtained, in general. In this paper, three new algorithms (called boundary point algorithms due to using certain boundary points of $C$ at each iterative step) for finding the minimum norm fixed point of $T$ are proposed and strong convergence theorems are proved under some assumptions. Since the algorithms in this paper do not involve $P_{C}$, they are easy to implement in actual computing programs.

MSC: $47 \mathrm{H} 09 ; 47 \mathrm{H} 10 ; 65 \mathrm{~K} 10$
\end{abstract}

Keywords: minimum norm fixed point; nonexpansive mapping; metric projection; boundary point algorithm; Hilbert space

\section{Introduction and preliminaries}

Let $H$ be a real Hilbert space with the inner product $\langle\cdot, \cdot\rangle$ and the norm $\|\cdot\|$, and let $C$ be a nonempty closed convex subset of $H$. Recall that a mapping $T: C \rightarrow C$ is nonexpansive if $\|T x-T y\| \leq\|x-y\|$ for all $x, y \in C$. We use Fix $(T)$ to denote a set of fixed points of $T$, i.e., $\operatorname{Fix}(T) \triangleq\{x \in C \mid T x=x\}$. Throughout this article, $\operatorname{Fix}(T)$ is always assumed to be nonempty.

For every nonempty closed convex subset $K$ of $H$, the metric (or nearest point) projection indicated by $P_{K}$ from $H$ onto $K$ can be defined, that is, for each $x \in H, P_{K} x$ is the only point in $K$ such that $\left\|x-P_{K} x\right\|=\inf \{\|x-z\| \mid z \in K\}$. It is well known (e.g., see [1]) that $P_{K}$ is nonexpansive and a characteristic inequality holds.

Lemma 1.1 Let $K$ be a closed convex subset of a real Hilbert space $H$. Given $x \in H$ and $z \in K$. Then $z=P_{K} x$ if and only if there holds the relation

$$
\langle x-z, y-z\rangle \leq 0, \quad \forall y \in K .
$$

Since $\operatorname{Fix}(T)$ is a closed convex subset of $H$, so the metric projection $P_{\mathrm{Fix}(T)}$ is valid and thus there exists a unique element, denoted by $x^{\dagger}$, in Fix $(T)$ such that $\left\|x^{\dagger}\right\|=\inf _{x \in \operatorname{Fix}(T)}\|x\|$,

\section{空 Springer}

○2014 He and Yang; licensee Springer. This is an Open Access article distributed under the terms of the Creative Commons Attribution License (http://creativecommons.org/licenses/by/2.0), which permits unrestricted use, distribution, and reproduction in any medium, provided the original work is properly cited. 
that is, $x^{\dagger}=P_{\mathrm{Fix}(T)} 0 \cdot x^{\dagger}$ is called a minimum norm fixed point of $T$. Because the minimum norm fixed point of a nonexpansive mapping is closely related to convex optimization problems, it is favored by people.

An extensive literature on iteration methods for fixed point problems of nonexpansive mappings has been published (for example, see [1-17]). Many iteration processes are often used to approximate a fixed point of a nonexpansive mapping in a Hilbert space or a Banach space. One of them is now known as Halpern's iteration process [2] and is defined as follows: take an initial guess $x_{0} \in C$ arbitrarily and define $\left\{x_{n}\right\}$ recursively by

$$
x_{n+1}=t_{n} u+\left(1-t_{n}\right) T x_{n}, \quad n=0,1,2, \ldots,
$$

where $\left\{t_{n}\right\}$ is a sequence in the interval $[0,1]$ and $u$ is some given element in $C$. For Halpern's iteration process, a classical result is as follows.

Theorem 1.2 $([13,14])$ If $\left\{t_{n}\right\}$ satisfies the conditions:

(i) $t_{n} \rightarrow 0(n \rightarrow \infty)$;

(ii) $\sum_{n=1}^{\infty} t_{n}=\infty$;

(iii) $\lim _{n \rightarrow \infty} \frac{t_{n+1}}{t_{n}}=1$ or $\sum_{n=1}^{\infty}\left|t_{n+1}-t_{n}\right|<\infty$;

then the sequence $\left\{x_{n}\right\}$ generated by (1.1) converges strongly to a fixed point $x^{*}$ of $T$ such that $x^{*}=P_{\operatorname{Fix}(T)} u$, that is,

$$
\left\|u-x^{*}\right\|=\inf _{x \in \operatorname{Fix}(T)}\|u-x\| .
$$

Now we consider how to get the minimum norm fixed point of $T$. In the case where $0 \in C$, taking $u=0$ in (1.1), we assert by using Theorem 1.2 that $\left\{x_{n}\right\}$ generated by (1.1) converges strongly to $x^{\dagger}$ under conditions (i)-(iii) above. But, in the case where $0 \notin C$, the iteration process $x_{n+1}=\left(1-t_{n}\right) T x_{n}$ becomes invalid because $x_{n}$ may not belong to $C$. In order to overcome this weakness, Wang and $\mathrm{Xu}$ [15] introduced the iteration process

$$
x_{n+1}=P_{C}\left(1-t_{n}\right) T x_{n}, \quad n=1,2, \ldots
$$

They proved that if $\left\{t_{n}\right\}$ satisfies the same conditions in Theorem 1.2, then the sequence $\left\{x_{n}\right\}$ generated by (1.2) converges strongly to $x^{\dagger}$.

However, it is difficult to implement the iteration process (1.2) in actual computing programs because the specific expression of $P_{C}$ cannot be obtained, in general.

The purpose of this paper is to propose three new algorithms for finding the minimum norm fixed point of $T$. The strong convergence theorems are proved under some assumptions. The main advantage of the algorithms in this paper is that they have nothing to do with the metric projection $P_{C}$ and thus they are easy to implement in actual computing programs. Because the key of our algorithms is replacing a fixed element $u$ in (1.1) by a certain sequence $\left\{u_{n}\right\}$ in the boundary of $C$, they are called boundary point algorithms.

We will use the following notations:

1. $\rightarrow$ for weak convergence and $\rightarrow$ for strong convergence.

2. $\omega_{w}\left(x_{n}\right)=\left\{x \mid \exists\left\{x_{n_{k}}\right\} \subset\left\{x_{n}\right\}\right.$ such that $\left.x_{n_{k}} \rightarrow x\right\}$ denotes the weak $\omega$-limit set of $\left\{x_{n}\right\}$.

3. $A \triangleq B$ means that $B$ is the definition of $A$.

We need some facts and tools in a real Hilbert space $H$ which are listed as lemmas below. 
Lemma 1.3 ([18]) Let $C$ be a closed convex subset of a real Hilbert space $H$, and let $T$ : $C \rightarrow C$ be a nonexpansive mapping such that $\operatorname{Fix}(T) \neq \emptyset$. If a sequence $\left\{x_{n}\right\}$ in $C$ is such that $x_{n} \rightarrow z$ and $\left\|x_{n}-T x_{n}\right\| \rightarrow 0$, then $z=T z$.

Lemma 1.4 There holds the identity in a real Hilbert space $H$ :

$$
\|u-v\|^{2}=\|u\|^{2}-\|v\|^{2}-2\langle v, u-v\rangle, \quad u, v \in H .
$$

Lemma 1.5 ([12,19]) Assume that $\left\{a_{n}\right\}$ is a sequence of nonnegative real numbers satisfying the property

$$
a_{n+1} \leq\left(1-\gamma_{n}\right) a_{n}+\gamma_{n} \delta_{n}+\sigma_{n}, \quad n=0,1,2, \ldots
$$

If $\left\{\gamma_{n}\right\}_{n=1}^{\infty} \subset(0,1),\left\{\delta_{n}\right\}_{n=1}^{\infty}$ and $\left\{\sigma_{n}\right\}_{n=1}^{\infty}$ satisfy the conditions:

(i) $\sum_{n=1}^{\infty} \gamma_{n}=\infty$,

(ii) $\limsup _{n \rightarrow \infty} \delta_{n} \leq 0$,

(iii) $\sum_{n=1}^{\infty}\left|\sigma_{n}\right|<\infty$,

then $\lim _{n \rightarrow \infty} a_{n}=0$.

\section{Main results}

In this section, $C$ is always assumed to be a nonempty closed convex subset of $H$ such that $0 \notin C$. We use $\partial C$ to denote the boundary of $C$. In order to give our main results, we first introduce a function $h: C \rightarrow(0,1]$ by the definition

$$
h(x)=\inf \{\lambda \in(0,1] \mid \lambda x \in C\}, \quad \forall x \in C .
$$

It is easy to see that $h(x) x \in \partial C$ and $h(x)>0$ hold for each $x \in C$ due to the assumption $0 \notin C$.

Since our iteration processes will involve the function $h(x)$, it is necessary to explain how to calculate $h(x)$ for any given $x \in C$ in actual computing programs. In order to get the value $h(x)$ for a given $x \in C$, we often need to deal with an algebraic equation. But dealing with an algebraic equation is easier than calculating the metric projection $P_{C}$, in general. To illustrate this viewpoint, let us consider the following simple example.

Example 1 Let $H$ be a real Hilbert space. Define a convex function $\varphi: H \rightarrow R^{1}$ by

$$
\varphi(x)=\left\|x-x_{0}\right\|^{2}+\langle x, u\rangle, \quad \forall x \in H,
$$

where $x_{0}$ and $u$ are two given points in $H$ such that $\left\langle x_{0}, u\right\rangle<0$. Setting $C=\{x \in H \mid \varphi(x) \leq$ $0\}$, then it is easy to show that $C$ is a nonempty convex closed subset of $H$ such that $0 \notin C$ (note that $\varphi\left(x_{0}\right)=\left\langle x_{0}, u\right\rangle<0$ and $\varphi(0)=\left\|x_{0}\right\|^{2}>0$ ). For a given $x \in C$, we have $\varphi(x) \leq 0$. In order to get $h(x)$, let $\varphi(\lambda x)=0$, where $\lambda \in(0,1]$ is an unknown number. Thus we obtain an algebraic equation

$$
\|x\|^{2} \lambda^{2}+\left(\langle x, u\rangle-2\left\langle x, x_{0}\right\rangle\right) \lambda+\left\|x_{0}\right\|^{2}=0 .
$$


Consequently, we get

$$
\lambda=\frac{2\left\langle x, x_{0}\right\rangle-\langle x, u\rangle \pm \sqrt{\left(\langle x, u\rangle-2\left\langle x, x_{0}\right\rangle\right)^{2}-4\|x\|^{2}\left\|x_{0}\right\|^{2}}}{2\|x\|^{2}} .
$$

By the definition of $h$, we have

$$
h(x)=\frac{2\left\langle x, x_{0}\right\rangle-\langle x, u\rangle-\sqrt{\left(\langle x, u\rangle-2\left\langle x, x_{0}\right\rangle\right)^{2}-4\|x\|^{2}\left\|x_{0}\right\|^{2}}}{2\|x\|^{2}} .
$$

Next we give our first iteration process for finding the minimum norm fixed point of $T$ : take $u_{0} \in \partial C$ arbitrarily and define $\left\{x_{n}\right\}$ recursively by

$$
\left\{\begin{array}{l}
x_{n}=P_{\mathrm{Fix}(T)} u_{n}, \\
u_{n}=\lambda_{n} x_{n-1}
\end{array}\right.
$$

where $\lambda_{n}=h\left(x_{n-1}\right)(n \geq 1)$.

Remark 1 How to implement the iteration process (2.1)? In actual computing programs, we can use the standard Halpern's iteration process to get $x_{n}$ from $u_{n}$ for each $n \geq 0$. Indeed, taking $x_{n}^{(0)}=u_{n}$ and $\left\{x_{n}^{(m)}\right\}$ is generated inductively by

$$
x_{n}^{(m+1)}=t_{m} u_{n}+\left(1-t_{m}\right) T x_{n}^{(m)}, \quad m \geq 0,
$$

then, using Theorem 1.2, $x_{n}^{(m)} \rightarrow x_{n} \triangleq P_{\operatorname{Fix}(T)} u_{n}$ as $m \rightarrow \infty$. Thus we can take $x_{n}=x_{n}^{\left(M_{n}\right)}$ approximately for a sufficiently large integer $M_{n}$ in actual computing programs.

Geometric intuition seems to encourage us to guess $x_{n} \rightarrow P_{\mathrm{Fix}(T)} 0$ as $n \rightarrow \infty$ under some certain assumptions. As a matter of fact, it is true.

Theorem 2.1 If $\left\{\lambda_{n}\right\}$ satisfies $\sum_{n=1}^{\infty}\left(1-\lambda_{n}\right)=\infty$, then $\left\{x_{n}\right\}$ generated by (2.1) converges strongly to $x^{\dagger}=P_{\mathrm{Fix}(T)} 0$.

Proof Noticing the fact that $x^{\dagger}=P_{\mathrm{Fix}(T)} 0=P_{\mathrm{Fix}(T)} \lambda x^{\dagger}$ holds for all $\lambda \in[0,1]$, we have from (2.1) that

$$
\left\|x_{n}-x^{\dagger}\right\|=\left\|P_{\mathrm{Fix}(T)} u_{n}-x^{\dagger}\right\|=\left\|P_{\mathrm{Fix}(T)} \lambda_{n} x_{n-1}-P_{\mathrm{Fix}(T)} \lambda_{n} x^{\dagger}\right\| \leq \lambda_{n}\left\|x_{n-1}-x^{\dagger}\right\|,
$$

consequently,

$$
\left\|x_{n}-x^{\dagger}\right\| \leq \lambda_{n} \lambda_{n-1} \cdots \lambda_{2} \lambda_{1}\left\|x_{0}-x^{\dagger}\right\|
$$

Thus this together with the condition $\sum_{n=1}^{\infty}\left(1-\lambda_{n}\right)=\infty$ leads to the conclusion.

Remark 2 Is the condition $\sum_{n=1}^{\infty}\left(1-\lambda_{n}\right)=\infty$ reasonable? In other words, can we find an example which satisfies this condition? The answer is yes. The following result implies that this condition is not harsh. 
Corollary 1 If $d(\operatorname{Fix}(T), \partial C) \triangleq \inf \{\|x-y\| \mid x \in \operatorname{Fix}(T), y \in \partial C\}>0$, then $\left\{x_{n}\right\}$ generated by (2.1) converges strongly to $x^{\dagger}=P_{\mathrm{Fix}(T)} 0$.

Proof Obviously, it suffices to verify that if $d(\operatorname{Fix}(T), \partial C)>0$, then $\sum_{n=1}^{\infty}\left(1-\lambda_{n}\right)=\infty$. In fact, setting $d \triangleq d(\operatorname{Fix}(T), \partial C)>0$, we have from (2.1) and (2.2) that

$$
\lambda_{n}=\frac{\left\|u_{n}\right\|}{\left\|x_{n-1}\right\|}=\frac{\left\|x_{n-1}\right\|-\left\|x_{n-1}-u_{n}\right\|}{\left\|x_{n-1}\right\|} \leq 1-\frac{d}{\left\|x_{0}\right\|+\left\|x_{0}-x^{\dagger}\right\|},
$$

hence

$$
1-\lambda_{n} \geq \frac{d}{\left\|x_{0}\right\|+\left\|x_{0}-x^{\dagger}\right\|}
$$

This implies that $\sum_{n=1}^{\infty}\left(1-\lambda_{n}\right)=\infty$ holds.

Our second iteration process for finding the minimum norm fixed point of $T$ is defined by

$$
x_{n}=t_{n} \lambda_{n} x_{n-1}+\left(1-t_{n}\right) T x_{n}, \quad n \geq 1,
$$

where $\left\{t_{n}\right\} \subset(0,1), \lambda_{n}=h\left(x_{n-1}\right)(n \geq 1)$ and $x_{0}$ is taken in $C$ arbitrarily.

Remark 3 Equation (2.3) is an implicit iteration process. A natural question is how to get $x_{n}$ from $x_{n-1}$. Indeed, suppose that we have got $x_{n-1}$, define the mapping $T_{n}: C \rightarrow C$ by $T_{n}: x \mapsto t_{n} \lambda_{n} x_{n-1}+\left(1-t_{n}\right) T x(\forall x \in C)$, then $T_{n}$ is $\left(1-t_{n}\right)$-contractive and $x_{n}$ is just its unique fixed point. So we can use Picard's iteration process

$$
x_{n}^{(m+1)}=t_{n} \lambda_{n} x_{n-1}+\left(1-t_{n}\right) T x_{n}^{(m)}, \quad m \geq 0,
$$

to calculate $x_{n}$ approximately since $x_{n}^{(m)} \rightarrow x_{n}$ as $m \rightarrow \infty$, where $x_{n}^{(0)}$ can be taken in $C$ arbitrarily, for example, $x_{n}^{(0)}=x_{n-1}$.

Theorem 2.2 Assume that $\sum_{n=1}^{\infty}\left(1-\lambda_{n}\right)=\infty$ and $\sum_{n=1}^{\infty} t_{n}<\infty$, then $\left\{x_{n}\right\}$ generated by (2.3) converges strongly to $x^{\dagger}=P_{\operatorname{Fix}(T)} 0$.

Proof We first show that $\left\{x_{n}\right\}$ is bounded. Indeed, take a $p \in \operatorname{Fix}(T)$ to derive that

$$
\begin{aligned}
\left\|x_{n}-p\right\| & =\left\|t_{n} \lambda_{n}\left(x_{n-1}-p\right)+\left(1-t_{n}\right)\left(T x_{n}-p\right)-t_{n}\left(1-\lambda_{n}\right) p\right\| \\
& \leq t_{n} \lambda_{n}\left\|x_{n-1}-p\right\|+\left(1-t_{n}\right)\left\|x_{n}-p\right\|+t_{n}\left(1-\lambda_{n}\right)\|p\| .
\end{aligned}
$$

It follows that

$$
\left\|x_{n}-p\right\| \leq \lambda_{n}\left\|x_{n-1}-p\right\|+\left(1-\lambda_{n}\right)\|p\| .
$$

By induction,

$$
\left\|x_{n}-p\right\| \leq \max \left\{\left\|x_{1}-p\right\|,\|p\|\right\}
$$


and $\left\{x_{n}\right\}$ is bounded, so are $\left\{T x_{n}\right\}$. This together with (2.3) implies that $\left\|x_{n}-T x_{n}\right\| \rightarrow 0$ $(n \rightarrow \infty)$. Thus it follows from Lemma 1.3 that $\omega_{w}\left(x_{n}\right) \subset \operatorname{Fix}(T)$.

Next we show that

$$
\lim _{n \rightarrow \infty} \sup \left\langle-x^{\dagger}, x_{n}-x^{\dagger}\right\rangle \leq 0
$$

Indeed, take a subsequence $\left\{x_{n_{k}}\right\}$ of $\left\{x_{n}\right\}$ such that

$$
\lim _{n \rightarrow \infty} \sup \left\langle-x^{\dagger}, x_{n}-x^{\dagger}\right\rangle=\lim _{k \rightarrow \infty}\left\langle-x^{\dagger}, x_{n_{k}}-x^{\dagger}\right\rangle
$$

without loss of generality, we may assume that $x_{n_{k}} \rightarrow \bar{x}$. Noticing $x^{\dagger}=P_{\mathrm{Fix}(T)} 0$, we obtain from $\bar{x} \in \operatorname{Fix}(T)$ and Lemma 1.1 that

$$
\lim _{n \rightarrow \infty} \sup \left\langle-x^{\dagger}, x_{n}-x^{\dagger}\right\rangle=\left\langle-x^{\dagger}, \bar{x}-x^{\dagger}\right\rangle \leq 0
$$

Finally, we show that $\left\|x_{n}-x^{\dagger}\right\| \rightarrow 0(n \rightarrow \infty)$. As a matter of fact, we have by using Lemma 1.4 that

$$
\begin{aligned}
\left\|x_{n}-x^{\dagger}\right\|^{2}= & \left\|t_{n} \lambda_{n}\left(x_{n-1}-x^{\dagger}\right)+\left(1-t_{n}\right)\left(T x_{n}-x^{\dagger}\right)-t_{n}\left(1-\lambda_{n}\right) x^{\dagger}\right\|^{2} \\
\leq & \left\|t_{n} \lambda_{n}\left(x_{n-1}-x^{\dagger}\right)+\left(1-t_{n}\right)\left(T x_{n}-x^{\dagger}\right)\right\|^{2} \\
& +2 t_{n}\left(1-\lambda_{n}\right)\left(-x^{\dagger}, x_{n}-x^{\dagger}\right\rangle \\
\leq & t_{n}^{2} \lambda_{n}^{2}\left\|x_{n-1}-x^{\dagger}\right\|^{2}+\left(1-t_{n}\right)^{2}\left\|x_{n}-x^{\dagger}\right\|^{2} \\
& +2 t_{n} \lambda_{n}\left(1-t_{n}\right)\left\|x_{n-1}-x^{\dagger}\right\| \cdot\left\|x_{n}-x^{\dagger}\right\| \\
& +2 t_{n}\left(1-\lambda_{n}\right)\left\langle-x^{\dagger}, x_{n}-x^{\dagger}\right\rangle .
\end{aligned}
$$

Hence,

$$
\begin{aligned}
\left(2-t_{n}\right)\left\|x_{n}-x^{\dagger}\right\|^{2} \leq & t_{n} \lambda_{n}^{2}\left\|x_{n-1}-x^{\dagger}\right\|^{2}+2 \lambda_{n}\left(1-t_{n}\right)\left\|x_{n-1}-x^{\dagger}\right\| \cdot\left\|x_{n}-x^{\dagger}\right\| \\
& +2\left(1-\lambda_{n}\right)\left\langle-x^{\dagger}, x_{n}-x^{\dagger}\right\rangle \\
\leq & t_{n} \lambda_{n}^{2}\left\|x_{n-1}-x^{\dagger}\right\|^{2}+\lambda_{n}^{2}\left\|x_{n-1}-x^{\dagger}\right\|^{2}+\left(1-t_{n}\right)^{2}\left\|x_{n}-x^{\dagger}\right\|^{2} \\
& +2\left(1-\lambda_{n}\right)\left\langle-x^{\dagger}, x_{n}-x^{\dagger}\right\rangle .
\end{aligned}
$$

Consequently,

$$
\begin{aligned}
\left\|x_{n}-x^{\dagger}\right\|^{2} \leq & {\left[1-\left(1-\lambda_{n}\right)\right]\left\|x_{n-1}-x^{\dagger}\right\|^{2}+2\left(1-\lambda_{n}\right)\left\langle-x^{\dagger}, x_{n}-x^{\dagger}\right\rangle } \\
& +t_{n}\left\|x_{n-1}-x^{\dagger}\right\|^{2} .
\end{aligned}
$$

Using Lemma 1.5, we conclude from (2.5) and conditions $\sum_{n=1}^{\infty}\left(1-\lambda_{n}\right)=\infty$ and $\sum_{n=1}^{\infty} t_{n}<$ $\infty$ that $x_{n} \rightarrow x^{\dagger}$.

By a similar argument as above, we easily get the following result. 
Corollary 2 If $d(R(T), \partial C) \triangleq \inf \{\|x-y\| \mid x \in \operatorname{Fix}(T), y \in \partial C\}>0$ and $\sum_{1}^{\infty} t_{n}<\infty$, then $\left\{x_{n}\right\}$ generated by (2.3) converges strongly to $x^{\dagger}=P_{\mathrm{Fix}(T)} 0$, where $R(T)$ is the range of $T$.

Proof It suffices to verify that $d(R(T), \partial C)>0$ implies $\sum_{n=1}^{\infty}\left(1-\lambda_{n}\right)=\infty$. Indeed,

$$
\lambda_{n}=\frac{\left\|u_{n}\right\|}{\left\|x_{n-1}\right\|}=\frac{\left\|x_{n-1}\right\|-\left\|x_{n-1}-u_{n}\right\|}{\left\|x_{n-1}\right\|}=1-\frac{\left\|x_{n-1}-T x_{n-1}+T x_{n-1}-u_{n}\right\|}{\left\|x_{n-1}\right\|} .
$$

Setting $d \triangleq d(R(T), \partial C)>0$, we have from (2.4) that

$$
1-\lambda_{n} \geq \frac{\left\|T x_{n-1}-u_{n}\right\|}{\left\|x_{n-1}\right\|}-\frac{\left\|x_{n-1}-T x_{n-1}\right\|}{\left\|x_{n-1}\right\|} \geq \frac{d}{\left\|x_{1}-x^{\dagger}\right\|+2\left\|x^{\dagger}\right\|}-\frac{\left\|x_{n-1}-T x_{n-1}\right\|}{d(0, C)} .
$$

Note that $\left\|x_{n-1}-T x_{n-1}\right\| \rightarrow 0$, it follows that $\sum_{n=1}^{\infty}\left(1-\lambda_{n}\right)=\infty$.

Finally, we propose an explicit iteration process for finding the minimum norm fixed point of $T$ which is defined by

$$
x_{n+1}=t_{n} \lambda_{n} x_{n}+\left(1-t_{n}\right) T x_{n}, \quad n \geq 0,
$$

where $\left\{t_{n}\right\} \subset(0,1), \lambda_{n}=h\left(x_{n}\right)(n \geq 0)$ and $x_{0}$ is taken in $C$ arbitrarily.

Theorem 2.3 Assume that $\left\{t_{n}\right\}$ and $\left\{\lambda_{n}\right\}$ satisfy the following conditions:

(i) $t_{n} \rightarrow 0$ and $\sum_{n=0}^{\infty} t_{n}=\infty$;

(ii) $\limsup _{n \rightarrow \infty} \lambda_{n} \leq \bar{\lambda}<1$;

(iii) $\sum_{n=1}^{\infty}\left|t_{n}-t_{n-1}\right|<\infty$ or $\lim _{n \rightarrow \infty} \frac{t_{n}}{t_{n-1}}=1$;

(iv) $\sum_{n=1}^{\infty} t_{n}\left|\lambda_{n}-\lambda_{n-1}\right|<\infty$ or $\lim _{n \rightarrow \infty} \frac{\lambda_{n}}{\lambda_{n-1}}=1$.

Then $\left\{x_{n}\right\}$ generated by (2.6) converges strongly to $x^{\dagger}=P_{\mathrm{Fix}(T)} 0$.

Proof We first show that $\left\{x_{n}\right\}$ is bounded. Indeed, we have by taking $p \in \operatorname{Fix}(T)$ arbitrarily that

$$
\begin{aligned}
\left\|x_{n+1}-p\right\| & \leq t_{n}\left\|\lambda_{n} x_{n}-p\right\|+\left(1-t_{n}\right)\left\|T x_{n}-p\right\| \\
& \leq t_{n}\left[\lambda_{n}\left\|x_{n}-p\right\|+\left(1-\lambda_{n}\right)\|p\|\right]+\left(1-t_{n}\right)\left\|x_{n}-p\right\| \\
& \leq t_{n} \max \left\{\left\|x_{n}-p\right\|,\|p\|\right\}+\left(1-t_{n}\right)\left\|x_{n}-p\right\| \\
& \leq \max \left\{\left\|x_{n}-p\right\|,\|p\|\right\} .
\end{aligned}
$$

Inductively,

$$
\left\|x_{n}-p\right\| \leq \max \left\{\left\|x_{0}-p\right\|,\|p\|\right\}, \quad n \geq 0 .
$$

This means that $\left\{x_{n}\right\}$ is bounded, so are $\left\{T x_{n}\right\}$.

We next show that $\left\|x_{n+1}-x_{n}\right\| \rightarrow 0$. Using (2.6), it follows from a direct calculation that

$$
\begin{aligned}
\left\|x_{n+1}-x_{n}\right\| & =\left\|\left[t_{n} \lambda_{n} x_{n}+\left(1-t_{n}\right) T x_{n}\right]-\left[t_{n-1} \lambda_{n-1} x_{n-1}+\left(1-t_{n-1}\right) T x_{n-1}\right]\right\| \\
& =\|\left(1-t_{n}\right)\left(T x_{n}-T x_{n-1}\right)-\left(t_{n}-t_{n-1}\right) T x_{n-1}+t_{n} \lambda_{n}\left(x_{n}-x_{n-1}\right)
\end{aligned}
$$




$$
\begin{aligned}
& +\left(t_{n} \lambda_{n}-t_{n-1} \lambda_{n-1}\right) x_{n-1} \| \\
\leq & {\left[1-t_{n}\left(1-\lambda_{n}\right)\right]\left\|x_{n}-x_{n-1}\right\|+\left|t_{n}-t_{n-1}\right|\left(\left\|T x_{n-1}\right\|+\lambda_{n-1}\left\|x_{n-1}\right\|\right) } \\
& +t_{n}\left|\lambda_{n}-\lambda_{n-1}\right| \cdot\left\|x_{n-1}\right\| .
\end{aligned}
$$

Using Lemma 1.5, we conclude from conditions (i)-(iv) that $\left\|x_{n+1}-x_{n}\right\| \rightarrow 0$. Noticing the boundedness of $\left\{x_{n}\right\}$ and $\left\{T x_{n}\right\}$ and condition (i), we have from (2.6) that $\left\|x_{n+1}-T x_{n}\right\| \rightarrow 0$. Consequently, $\left\|x_{n}-T x_{n}\right\| \rightarrow 0$. Using Lemma 1.3, we derive that $\omega_{w}\left(x_{n}\right) \subset \operatorname{Fix}(T)$.

Then we show that

$$
\lim _{n \rightarrow \infty} \sup \left\langle-x^{\dagger}, x_{n-1}-x^{\dagger}\right\rangle \leq 0
$$

As a matter of fact, this is derived by the same argument as in the proof of Theorem 2.3.

Finally, we show that $\left\|x_{n}-x^{\dagger}\right\| \rightarrow 0$. Using Lemma 1.4 and (2.6), it is easy to verify that

$$
\begin{aligned}
\left\|x_{n+1}-x^{\dagger}\right\|^{2}= & \left\|t_{n}\left(\lambda_{n} x_{n}-x^{\dagger}\right)+\left(1-t_{n}\right)\left(T x_{n}-x^{\dagger}\right)\right\|^{2} \\
\leq & \left(1-t_{n}\right)^{2}\left\|T x_{n}-x^{\dagger}\right\|^{2}+2 t_{n}\left(\lambda_{n} x_{n}-x^{\dagger}, x_{n+1}-x^{\dagger}\right\rangle \\
\leq & \left(1-t_{n}\right)^{2}\left\|x_{n}-x^{\dagger}\right\|^{2}+2 t_{n} \lambda_{n}\left\langle x_{n}-x^{\dagger}, x_{n+1}-x^{\dagger}\right\rangle \\
& +2 t_{n}\left(1-\lambda_{n}\right)\left\langle-x^{\dagger}, x_{n+1}-x^{\dagger}\right\rangle \\
\leq & \left(1-t_{n}\right)^{2}\left\|x_{n}-x^{\dagger}\right\|^{2}+2 t_{n} \lambda_{n}\left\|x_{n}-x^{\dagger}\right\| \cdot\left\|x_{n+1}-x^{\dagger}\right\| \\
& +2 t_{n}\left(1-\lambda_{n}\right)\left\langle-x^{\dagger}, x_{n+1}-x^{\dagger}\right\rangle .
\end{aligned}
$$

Hence,

$$
\left\|x_{n+1}-x^{\dagger}\right\|^{2} \leq\left(1-\gamma_{n}\right)\left\|x_{n}-x^{\dagger}\right\|^{2}+\gamma_{n} \sigma_{n}
$$

where

$$
\begin{aligned}
& \gamma_{n}=t_{n} \frac{2\left(1-\lambda_{n}\right)-t_{n}}{1-t_{n} \lambda_{n}}, \\
& \sigma_{n}=\frac{2\left(1-\lambda_{n}\right)}{2\left(1-\lambda_{n}\right)-t_{n}}\left\langle-x^{\dagger}, x_{n+1}-x^{\dagger}\right\rangle .
\end{aligned}
$$

It is easily seen that $\gamma_{n} \rightarrow 0, \sum_{n=0}^{\infty} \gamma_{n}=\infty$ by conditions (i) and (ii), and $\lim _{n \rightarrow \infty} \sup \sigma_{n} \leq 0$ by (2.7). By Lemma 1.5, we conclude that $x_{n} \rightarrow x^{\dagger}$.

\section{Competing interests}

The authors declare that they have no competing interests.

Authors' contributions

All authors contributed equally to the writing of this paper. All authors read and approved the final manuscript.

\section{Acknowledgements}

This work was supported in part by the Fundamental Research Funds for the Central Universities (3122013k004) and in part by the Foundation of Tianjin Key Lab for Advanced Signal Processing. 


\section{References}

1. Goebel, K, Reich, S: Uniform Convexity, Hyperbolic Geometry, and Nonexpansive Mappings. Dekker, New York (1984)

2. Halpern, B: Fixed points of nonexpanding maps. Bull. Am. Math. Soc. 73, 957-961 (1967)

3. Ishikawa, S: Fixed points by a new iteration method. Proc. Am. Math. Soc. 44, 147-150 (1974)

4. Mann, WR: Mean value methods in iteration. Proc. Am. Math. Soc. 4, 506-510 (1953)

5. Nakajo, K, Takahashi, W: Strong convergence theorems for nonexpansive mappings and nonexpansive semigroups. J. Math. Anal. Appl. 279, 372-379 (2003)

6. Reich, S: Weak convergence theorems for nonexpansive mappings in Banach spaces. J. Math. Anal. Appl. 67, 274-276 (1979)

7. Reich, S: Strong convergence theorem for resolvents of accretive operators in Banach spaces. J. Math. Anal. Appl. 75, 287-292 (1980)

8. Reich, S, Shemen, L: Two algorithms for nonexpansive mappings. Fixed Point Theory 12, 443-448 (2011)

9. Shioji, N, Takahashi, W: Strong convergence of approximated sequences for nonexpansive mappings in Banach spaces. Proc. Am. Math. Soc. 125, 3641-3645 (1997)

10. Tan, KK, Xu, HK: Approximating fixed points of nonexpansive mappings by the Ishikawa iteration process. J. Math. Anal. Appl. 178(2), 301-308 (1993)

11. Wittmann, R: Approximation of fixed points of nonexpansive mappings. Arch. Math. 58, 486-491 (1992)

12. Xu, HK: Iterative algorithms for nonlinear operators. J. Lond. Math. Soc. 66, 240-256 (2002)

13. Moudafi, A: Viscosity approximation methods for fixed points problems. J. Math. Anal. Appl. 241, 46-55 (2000)

14. Xu, HK: Viscosity approximation methods for nonexpansive mappings. J. Math. Anal. Appl. 298, 279-291 (2004)

15. Wang, F, Xu, HK: Approximating curve and strong convergence of the CQ algorithm for the split feasibility problem. J. Inequal. Appl. 2010, Article ID 102085 (2010). doi:10.1155/2010/102085

16. Diestel, J: Geometry of Banach Spaces - Selected Topics. Lecture Notes in Mathematics, vol. 485. Springer, Berlin (1975)

17. Beauzamy, B: Introduction to Banach Spaces and Their Geometry. North-Holland, Amsterdam (1982)

18. Goebel, K, Kirk, WA: Topics in Metric Fixed Point Theory. Cambridge Studies in Advanced Mathematics, vol. 28 Cambridge University Press, Cambridge (1990)

19. Liu, LS: Iterative processes with errors for nonlinear strongly accretive mappings in Banach spaces. J. Math. Anal. Appl. $194,114-125(1995)$

10.1186/1687-1812-2014-56

Cite this article as: He and Yang: Boundary point algorithms for minimum norm fixed points of nonexpansive

mappings. Fixed Point Theory and Applications 2014, 2014:56

\section{Submit your manuscript to a SpringerOpen ${ }^{\circ}$ journal and benefit from:}

- Convenient online submission

- Rigorous peer review

- Immediate publication on acceptance

- Open access: articles freely available online

- High visibility within the field

- Retaining the copyright to your article 